\title{
AVALIACÃO DO PENSAMENTO CRÍTICO E DA PRESENCA COGNITIVA EM FÓRUM DE DISCUSSÃO ONLINE
}

\author{
Autores: Elenise Maria de Araujo, \\ Fabiano Berardo de Souza, \\ José Dutra de Oliveira Neto
}

Palavras-chave: Fórum Socrático Cognitivo. Presença Cognitiva. Pensamento Crítico. Análise de conteúdo. Avaliação em EAD.

O fórum de discussão educativo configura-se em um espaço profícuo para o compartilhamento e a construção de conhecimentos em comunidades de aprendizagem. Porém, o número de mensagens nos fóruns educativos online gera uma sobrecarga de informação que dificulta a organização e a comunicação entre os membros, comprometendo, também, a eficácia do processo de avaliação da aprendizagem. Diante da necessidade de uma solução metodológica para o contexto da EAD no Brasil, realizou-se uma revisão de literatura sobre os modelos de organização, e o processo de análise das mensagens que envolvem os indicadores das habilidades da presença cognitiva (Garrison, Anderson e Archer, 2001) e o pensamento crítico (THE CRITICAL THINKING COMMUNITY (2011) e a dinâmica do questionamento socrático (Paul, 1993). Para mensurar esses indicadores faz-se necessário utilizar técnicas e métodos de análises sistemáticas (Garrison e Arbaugh, 2007; Lisbôa e Coutinho (2012) e Coutinho (2013) e definir um modelo estratégico para organização dos fóruns (Fucks, Gerosa e Lucena (2002). Os objetivos deste trabalho é propor e avaliar um novo modelo de fórum intitulado "Fórum Socrático Cognitivo- FSC" com uma metodologia de avaliação da presença cognitiva e dos níveis de pensamento crítico dos alunos em cursos superiores online. Para proposição do modelo FSC os procedimentos metodológicos envolveram: a revisão de literatura para demarcação do state of the art e dos principais modelos de fóruns e métodos de avaliação existentes; a identificação dos elementos essenciais do fórum online; a estrutura e a organização de fóruns; definição das relações entre o conjunto de categorias e fases do novo modelo de fórum, segundo a dinâmica de questionamento socrático e da presença cognitiva; identificação das principais características dos métodos de avaliação do modelo proposto. Para composição da metodologia de avaliação elaborou-se um grid de avaliação e a descrição dos requisitos metodológicos e técnicos que envolvem os princípios da lexicometria, da indexação, das análises textuais e estatísticas, modelos de regressão linear e redes complexas. Para comprovar a validade inicial da proposta foram aplicados o modelo FSC e a metodologia da avaliação em duas disciplinas do curso de aperfeiçoamento em EAD em 2011,2012 e 2013 de uma instituição de ensino superior vinculada a UAB do Brasil. Realizou-se a análise de 3.400 mensagens postadas por 544 alunos para verificar a partir de testes ANOVA, as relações de dependência entre a variável resposta "nota" e as covariáveis: conceitos, categorias de Garrison, tópicos socráticos, riqueza vocabular e sala (tutor). Analisou-se o conteúdo das mensagens, comparando a frequência das palavras-chaves expressas pelos alunos em relação aos conceitos expostos no texto científico adotado nas disciplinas. Para facilitar a visualização do desempenho dos alunos nos fóruns, foram construídas redes 
complexas formadas nas comunidades virtuais de aprendizagem. Para efeito comprovatório analisou-se uma amostra de $20,6 \%$ das redes comparando a média de notas obtidas nas disciplinas e o grau de centralidade apresentada pelos alunos nas redes complexas construídas. Os resultados obtidos na análise textual comprovam que existe correspondência entre as frases-indícios das categorias socráticas e os indicadores da presença cognitiva. A fase de exploração apresenta menor relevância quando comparada às fases de integração e de resolução do modelo Practical Inquiry visto que as mensagens postadas demonstram maior disposição para resolução de problemas, e para reflexão sobre pontos de vista diferentes. A partir dos dados estatísticos construíram-se 2 modelos de regressão linear e 136 redes complexas que permitiram confirmar os testes ANOVA utilizados na avaliação de desempenho dos alunos. As covariáveis conceitos, categorias de Garrison e sala (tutor) apresentaram nível de significância positivo na associação com a nota final do aluno. Os percentuais obtidos no cálculo da riqueza vocabular podem ser considerados indicadores da percepção de conceitos, pois os alunos expressam na escrita, conceitos elaborados intrinsecamente, e o processo cognitivo da linguagem de intercambiar palavras por seus sinônimos, aponta maior habilidade de coesão e são elencadas por Bloom (1983, 1956C) como requisitos mínimos do domínio cognitivo. O uso dessas palavras únicas ou isoladas confere ao dataset message características de conceituação de espontaneidade ao processo cognitivo da linguagem e o desempenho em escrita. Os resultados da análise comprovatória, confirmaram que os alunos que atingiram maior média final são aqueles que também demonstraram maior grau de centralidade sendo várias vezes citados por vários alunos e proporcionando assim maior desenvolvimento na comunidade de aprendizagem. As discussões nos fóruns promovem em todas as salas um processo de articulação do conhecimento a partir do qual os alunos fazem analogias, constroem novos modelos e compartilham informações extras sobre o tema. A estratégia de questionamento socrático difere do método convencional de discussão online em termos de complexidade, pois cada categoria de pergunta está ligada a uma diferente fase da presença cognitiva com o objetivo de apoiar o desenvolvimento de todos os alunos. Considera-se que as análises textuais e estatísticas e a construção das redes complexas atestam a relevância dos indicadores de avaliação que devem ser incentivas durante os fóruns de discussão em cursos online. Conclui-se que o modelo FSC contribui para o desenvolvimento das habilidades de expressão e comunicação de conceitos abordados na disciplina e colabora na avaliação do pensamento crítico e da presença cognitiva do aluno nos fóruns online.

Referências bibliográficas:

BLOOM, B. S. et al. Taxonomia de objetivos educacionais: compêndio primeiro-domínio cognitivo. Porto Alegre: Globo, 1983.

COUTINHO, C. P. Análise de conteúdo da comunicação assíncrona: considerações metodológicas e recomendações práticas. Educação, Formação \& Tecnologias, Lisboa, v. $6, \quad$ n. $1, \quad$ p. 21-34, $2013 . \quad$ Disponível em: <http://repositorium.sdum.uminho.pt/xmlui/bitstream/handle/1822/27071/319-1845-1PB.pdf?sequence=1>. Acesso em: 12 maio 2014. 
THE CRITICAL THINKING COMMUNITY. Foundation for Critical Thinking. 2011. Disponível em: <http://www.criticalthinking.org/articles/the-role-socratic-questioningttl.cfm>. Acesso em: 11 ago. 2012.

FUCKS, H.; GEROSA, M. A.; LUCENA, C. J. P. Usando a categorização e estruturação de mensagens textuais em cursos pelo Ambiente AulaNet. Revista Brasileira de Informática na Educação, v. 10, n. 1, p. 33-44, abr. 2002.

GARRISON, D. R.; ANDERSON, T.; ARCHER, W. Critical thinking, cognitive presence, and computer conferencing in distance education. American Journal of Distance Education, Philadelphia, v. 15, n. 1, p. 7-23, 2001.

GARRISON, D. R.; ARBAUGH, J. B. Researching the community of inquiry framework: review, issues, and future directions. Internet and Higher Education, Oxford, v. 10, n. 3 , p. 157-172, 2007.

LISBÔA, E. S.; COUTINHO, C. P. Tools for evaluation of learning in online discussion forums: a practical and theoretical contribution. Revista EducaOnline, Rio de Janeiro, v. 6, n. 3, p. 86-104, 2012.

PAUL, R. Critical thinking: what every person needs to survive in a rapidly changing world. Rohnert Park: Centre for Critical Thinking and Moral Critique, 1993. 